\title{
RECUPERACIÓN DE OVOCITOS RECOLECTADOS DE VACAS CRIOLLAS POST MÓRTEM DEL SUR DEL PERÚ
}

Responsable: MVZ. Nicolás Velarde Choque Miembro: MVZ. Daniel Gandarillas Espezúa

\begin{abstract}
RESUMEN
En el Laboratorio de Reproducción Animal de la Universidad Nacional Jorge Basadre Grohmann, durante los meses de abril a diciembre del año 2005 , se efectuó el procesamiento de ovarios procedentes del Camal Municipal de llave.

Se procesaron muestras de dos razas: criolla y Brown Swiss.

Las muestras se obtuvieron por las técnicas de aspiración y corte seriado del ovario.

La técnica empleada de corte seriado tuvo mejores resultados en comparación con la técnica de aspiración.

En animales mayores de ocho años se dificulta la recuperación de ovocitos.
\end{abstract}

\begin{abstract}
At the animal reproduction laboratory at Jorge Basadre Grohmann University, an ovary sample process took place from April to December 2005, these samples came from the municipal slaughterhouse in llave.
\end{abstract}

Two samples were processed, one of Creole breed and the other of Brown Swiss. The samples were got by the follicle aspiration techniques and ovary serial cut.

The serial cut technique used got better results compared to the aspiration technique. In animals older than eight

\section{INTRODUCCIÓN}

La aplicación de los procedimientos de fertilización in vitro (FTV) en la reproducción bovina se ha incrementado en los últimos años y en un futuro puede llegar a ser utilizada en programas de gran escala en la producción comercial de embriones in vitro. Dentro de este concepto, la recolección de ovocitos es un paso necesario para poder llegar a establecer estos programas de FIV.

Los ovarios contienen un elevado número de folículos que se encuentran en diferentes estados de desarrollo (primordiales, en crecimiento, atrésicos), de los cuales solamente una pequeña proporción va a ser utilizada durante la vida reproductiva del animal. La recolección de ovocitos permite recuperar y aprovechar folículos no ovulatorios, que bajo condiciones fisiológicas se tornarian en folículos atrésicos.

La obtención de ovarios provenientes de vacas sacrificadas en el matadero suministra una fuente abundante de ovocitos obtenidos a bajo costo, provenientes de animales en diferentes estados del ciclo estral, que pueden ser madurados, fertilizados y cultivados in vitro hasta estados avanzados del desarrollo embrionario.

\section{OBJETIVOS}

1. Recuperación de ovocitos de vacas sacrificadas.

2. Acondicionar técnicas adecuadas para la recuperación y manipulación de los ovocitos.

\section{MATERIAL Y MÉTODOS}

\section{Recolección de ovarios en animales postmórtem}

Se colectaron muestras procedentes del Camal Municipal de llave, provincia del Collao, Puno, que beneficia al ganado de vacuno los días viernes.

Las muestras para su envio se acondicionaron en envases especiales, los ovarios sumergidos en solución salina, para su posterior procesamiento en el Laboratorio de Reproducción Animal de la UNJBG-Tacna.

Así mismo se preparó el medio buffer para la manipulación de los ovocitos, del mismo se prepararon las placas tipo reloj y placas petri, se adecuaron las jeringas para una mejor manipulación de los ovocitos.

Los ovocitos se obtuvieron por dos métodos: 
método de corte seriado de ovarios de seis animales de raza criolla y el método de aspiración con jeringa de folículos superficiales en diez animales de la raza Brown Swiss.

\section{Método de Corte Seriado:}

Los ovarios se transportaron al Laboratorio en solución salina suplementada con antibióticos. En el Laboratorio se hace remoción del tejido adyacente, del cuerpo lúteo y de sangre con lavados de solución salina.

El método de corte seriado consiste en colocar cada uno de los ovarios en placas petri que contienen la solución, se corta la superficie y el interior de los ovarios a lo largo y a través de éste con cuchillas separadas por $2 \mathrm{~mm}$ aproximadamente.

\section{Método de Aspiración:}

Se someten a este procedimiento folículos superficiales visibles con jeringas de 5-10 cc y agujas calibre $18 \mathrm{G}$.

\section{RESULTADOS:}

TABLA N001 Rendimiento por corte Seriado en Vacas Criollas

\begin{tabular}{|l|c|c|}
\hline Diametro folicular & Foliculositotal de vacas & Total de ovocitos/foliculos \\
\hline $\begin{array}{l}<\text { a } 2 \mathrm{~mm} \\
n=25\end{array}$ & 4,1 & 0,48 \\
\hline $\begin{array}{l}2 \mathrm{a} 3 \mathrm{~mm} \\
n=13\end{array}$ & 2,1 & 0,61 \\
\hline $\begin{array}{l}>\mathrm{a} 3 \mathrm{~mm} \\
n=13\end{array}$ & 2,1 & 0,38 \\
\hline
\end{tabular}

TABLA N02 Rendimiento por aspiración en vacas Brown Swiss

\begin{tabular}{|l|l|l|}
\hline Diámetro folicular & Foliculos/total de vacas & Total de ovocitos/foliculos \\
\hline $\begin{array}{l}\text { ra } 2 \mathrm{~mm} \\
n=39\end{array}$ & 3,9 & 0,30 \\
\hline $\begin{array}{l}2 \mathrm{a} 3 \mathrm{~mm} \\
n=45\end{array}$ & 4,5 & 0,31 \\
\hline $\begin{array}{l}\text { >3 } 3 \mathrm{~mm} \\
n=42\end{array}$ & 4,2 & 0,26 \\
\hline
\end{tabular}

Los resultados indican que con el método de corte, de foliculos se obtiene una mayor proporción de ovocitos y de excelente calidad (Tabla No1), Foto №1 para estudios in vitro comparado con el método de aspiración (Tabla $\mathrm{N}^{\circ} 02$ ). La disminución en las tasas de recuperación en el caso de aspiración folicular puede estar asociada a efectos nocivos sobre las capas de las células del cúmulus ejercidas por la fuerza de la aspiración.

Por otra parte, el mayor número de ovocitos obtenidos por el método de corte seriado puede estar explicado por la recuperación de ovocitos provenientes de foliculos menores de $2 \mathrm{~mm}$ de diámetro que están en el interior del ovario; sin embargo, estos ovocitos tienen poco potencial para sufrir maduración meiótica y desarrollo embrionario comparado con los ovocitos recuperados de los folículos presentes en la superficie del ovario, ya que los ovocitos de folículos internos pueden no haber adquirido aun la competencia para la maduración y desarrollo.

Asi mismo se han encontrado tres ovarios sin estructuras ováricas.

\section{v. DISCUSIÓN}

Los resultados encontrados no coinciden con lo reportado por Takagi et. al. que menciona mayores valores para el método de aspiración, que para el método de corte seriado. Esto podría deberse a la edad de los animales, ya que en el presente estudio se trabajó con animales mayores de ocho años.

\section{CONCLUSIONES}

1. La recuperación de ovocitos, tanto en la raza criolla como en la Brown Swiss, es factible en animales beneficiados.

2. Tanto las técnicas de aspiración como las de corte seriado son efectivas para la recuperación de ovocitos.

3. En los animales de más de ocho años de edad, disminuye la recuperación por efecto de la edad.

\section{BIBLIOGRAFÍA}

Cole y Cupps (1996). Reproducción animal. Editorial Interamericana, cuarta edición.

Hafez Ese(2002). Reproducción e inseminación artificial en animales. Editorial Mc. Graw Hill séptima edición, México.

Nalbandov, A. 1969. Fisiología de la reproducción. Editorial Acribia, España.

Takagi Y., K. Mori, T. Takahashi, S. Sugawara, Y J. Masaki (1992). Differences in development of bovine oocytes. Recovered by aspiration or by Mincing. J.Anim. Sci. 